\section{Organizações indígenas e distritalização sanitária: os riscos de "fazer ver" e "fazer crer" nas políticas de saúde}

\author{
Indigenous organizations and health district \\ apportionment: the gap between seeing \\ and believing in health policies
}

\author{
1 Núcleo de Estudos em \\ Saúde Pública, Universidade \\ Federal do Amazonas, \\ Manaus, Brasil. \\ 2 Centro de Pesquisas \\ Leônidas \& Maria Deane, \\ Fundação Oswaldo Cruz, \\ Manaus, Brasil. \\ Correspondência \\ L. Garnelo \\ Núcleo de Estudos em \\ Saúde Pública, Universidade \\ Federal do Amazonas. \\ Rua Dr. Afonso Pena 1053, \\ Io andar, Manaus \\ 69020-160, Brasil. \\ garnelo@netium.com.br
}

\begin{abstract}
This study aims to analyze the ethno-political, ethical, and health repercussions, for indigenous peoples' organizations involved in agreements with the Ministry of Health, resulting from the implementation of Special Indigenous Health Districts (DSEI) in the State of Amazonas, Brazil. The DSEIs chosen for analysis were those of Manaus and Rio Negro. Data were collected from reports drafted during and after planning and other meetings of the respective indigenous peoples' organizations, participatory observation in events organized to evaluate the health district apportionment process, and interviews with indigenous and non-indigenous managers of DSEIs. The article discusses the ambiguity of indigenous peoples' organizations in having to exercise their own political role while implementing a state policy, assumed as a way to overcome the stigma of their presumed inability to head the process of implementing a DSEI.
\end{abstract}

Health Policy; South American Indians; Organizations
Luiza Garnelo 1,2

Sully Sampaio ${ }^{1}$

\section{Introdução}

Este trabalho se propõe a analisar repercussões etnopolíticas, éticas e sanitárias nas práticas das organizações indígenas ligadas ao processo de implantação dos Distritos Sanitários Especiais Indígenas (DSEI) no Estado do Amazonas, Brasil. Após uma discussão mais geral do cenário da distritalização, será efetuado um enfoque mais detalhado sobre sua atuação em dois distritos sanitários: o de Manaus e o do Rio Negro, visando apreender as interações entre as políticas sanitárias e as relações de poder dos povos indígenas e suas entidades representativas.

As informações aqui trabalhadas foram obtidas através de análise documental de relatórios de encontros, de reuniões de planejamento e de gestão das convenentes indígenas, e da observação participante de eventos que buscavam avaliar o processo de distritalização (a saber: Coordenação das Organizações Indígenas da Amazônia Brasileira. Relatório Final do Encontro Macro Regional preparatório para a III Conferência Nacional de Saúde Indígena; 2001. Coordenação das Organizações Indígenas da Amazônia Brasileira. Relatório Analítico Descritivo do Convênio COIAB-FUNASA; 2002. Coordenação das Organizações Indígenas da Amazônia Brasileira. Relatório do Encontro das Organizações Indígenas Conveniadas com a FUNASA: Resultados e Desafios do Programa dos Distritos Sanitários Especiais Indígenas no Aten- 
dimento da Saúde dos Povos Indígenas; 2001. Conselho Distrital de Manaus. Ata da X Reunião Ordinária; 2002. Fundação Nacional de Saúde. Plano Distrital do DSEI Rio Negro; 2001. Fundação Nacional de Saúde. Plano Distrital do DSEI Rio Negro; 2002. Fundação Nacional de Saúde. Plano Distrital do DSEI Manaus; 2001. Fundação Nacional de Saúde. Plano Distrital do DSEI Manaus; 2002. Ministério da Saúde/ Fundação Nacional de Saúde. Relatório Final da III Conferência Nacional de Saúde dos Povos Indígenas; 2001. Cartas escritas por chefias de aldeia para a Coordenação das Organizações Indígenas da Amazônia Brasileira ao longo dos anos de 2000 e 2001. Carta de Brás de Oliveira França para o Presidente da Federação das Organizações Indígenas do Rio Negro, em setembro de 2001). Além disso, foram entrevistados gerentes indígenas e não indígenas dos distritos e servidores da Fundação Nacional de Saúde (FUNASA) que ocupam cargos de decisão na execução dessa política pública.

\section{O contexto da distritalização sanitária no Brasil}

A implantação dos DSEI, pela FUNASA, se iniciou em 1991 com o Decreto $n$. 23 do governo Collor e se consolidou com a Lei Arouca que, em 1999, regulamentou as atribuições ministeriais para implantação de um subsistema de atenção diferenciada à saúde, baseado na distritalização sanitária 1 (sobre a distritalização sanitária no SUS ver Mendes 2, Teixeira et al. 3 e Teixeira \& Melo 4).

A partir de 1999, a FUNASA viabilizou um modelo de atenção que optou pela renúncia à execução direta de serviços, adotando a estratégia de terceirização (para fins deste texto, consideraremos a terceirização como o processo político-administrativo de transferência total ou parcial das atribuições essenciais do Estado para a esfera privada) das ações de saúde a serem desenvolvidas em áreas indígenas. A pactuação entre governo e entidade prestadora de serviços vem sendo viabilizada na região Norte do país, principalmente através de convênios com entidades não-governamentais. A essas últimas competiria, mediante a aplicação de recursos oriundos do SUS, executar atividades preventivas e curativas dirigidas à população indígena aldeada. O planejamento das rotinas é ordenado num plano distrital renovado anualmente - da mesma forma que o convênio - e aprovado no conselho distrital.

A forma assumida pela terceirização em saúde indígena não encontra correspondente em qualquer outra área do SUS, que mantém a compra de serviços de entidades privadas, mas sem renunciar a execução direta de ações através de serviços próprios. Na relação dos órgãos do governo federal com os níveis estaduais e municipais de comando do SUS, a celebração de convênios foi superada com a Programação Pactuada Integrada (PPI) da gestão plena e básica da atenção e o repasse direto de recursos para os fundos de saúde, agilizando o financiamento dos sistemas locais, garantindo a continuidade das programações e a fixação de equipes capacitadas para a execução das ações. Esses mecanismos de gestão são próprios das relações entre os diferentes níveis de comando federal, estadual e municipal - do SUS, não podendo ser replicados nas pactuações entre governo e entidades civis que permanecem sendo reguladas por convênios.

Estudando a política de saúde do Brasil nos anos 90 , Noronha \& Soares 5 demonstram a influência da política neoliberal na redução do papel do Estado e na transferência da responsabilidade sanitária para entidades de direito privado ${ }^{6}$. São proposições que corroboram as análises de Fernandes 7 e Magalhães 8 sobre o repasse gradativo de suas funções públicas para o terceiro setor, caracterizado por Fernandes 7 (p. 21) como “um conjunto de organizações e iniciativas privadas que visam à produção de bens e serviços públicos".

Tais pressupostos se mantêm no subsistema de saúde indígena, mas a paradoxal relação da FUNASA com as conveniadas indígenas tende a moldar sua atuação para atender à execução de políticas e interesses do Estado, gerando um atrelamento a prioridades políticas definidas em espaços exteriores aos grupos étnicos.

No caso específico dos convênios firmados com organizações não-governamentais no Amazonas, o modelo também tem gerado rotatividade de pessoal, descontinuidade das ações, dificuldade de articulação com os níveis de referência dos órgãos estaduais e municipais de saúde e tendência à pulverização e descoordenação dos serviços intradistritais. Ao incorporar a execução de políticas públicas, as conveniadas são lançadas num dilema ético, pois assumem recursos e responsabilidades do Estado, passando a partilhar a rigidez burocrática das estruturas de governo e as contradições do neoliberalismo, que forçou a adoção de modelos de atenção à saúde contrários aos princípios de universalização e de publicização do SUS.

Esses novos papéis geram contradições em sua militância política, pois se, por um lado, elas desenvolvem lutas pela garantia de direitos civis - como o direito à saúde - por outro, se tor- 
nam prestadoras de serviços, assumindo a peculiar atribuição de cobrar e fiscalizar seu próprio desempenho.

Além disso, as responsabilidades do convênio de saúde geram um redimensionamento de seu perfil de atuação, obrigando as conveniadas a um aprimoramento da gestão administrativa para responder às complexas demandas de programação e de prestação de contas de recursos públicos. Seus dirigentes passam a coordenar a atuação de um grande número de profissionais de saúde, que trazem para o espaço das negociações etnopolíticas suas demandas e lógicas próprias de atuação, as quais nem sempre se harmonizam com as prioridades da entidade.

Segundo Garnelo 9, as relações conveniais vêm determinando o ritmo de trabalho das entidades forçando-as ao cumprimento de programações, metas, prazos e orçamentos definidos em planos distritais que em nada se assemelham as suas rotinas administrativas prévias. Além disso, o ônus político, decorrente de cortes no orçamento, atrasos no repasse de recursos, conflitos trabalhistas, dificuldades de referência e contra-referência, recai sobre a prestadora de serviço, que é, para o usuário, a face visível do subsistema de saúde indígena.

Politicamente o ônus também se revela na influência potencial que as autoridades governamentais podem exercer na atuação das convenentes. Ao longo de seu processo organizativo, o movimento indígena tem travado severos embates com a política indigenista, historicamente lesiva aos seus interesses 10 . Se anteriormente as posições e oposições às políticas de governo eram claramente delimitadas, hoje o quadro é marcado pela ambigüidade, na medida em que interesses e posições indígenas e estatais se misturam e tendem a confundir-se no processo de terceirização. A responsabilidade gerada pelas funções sociais da ação sanitária, pela complexidade técnica das ações programadas e dos intrincados mecanismos de movimentação e prestação de contas de recursos públicos exige um grande esforço de dirigentes e instituições, gera o risco de relegar outras atribuições das entidades a um plano secundário e de produzir uma burocracia indígena voltada para a condução de processos técnico-administrativos com pouca aderência às prioridades político-comunais.

\section{Organizações indígenas e distritalização no Amazonas}

O cenário acima descrito se reproduz no Amazonas, onde diversas entidades indígenas passaram a responsabilizar-se pela execução integral das ações de saúde em vários distritos sanitários. Sem perder de vista outras realidades, será feita uma análise mais detalhada de duas convenentes indígenas, a Coordenação das Organizações Indígenas da Amazônia Brasileira (COIAB) e a Federação das Organizações Indígenas do Rio Negro (FOIRN).

A COIAB, uma das primeiras organizações indígenas a firmar convênio com a FUNASA, se responsabilizou pela execução de ações de saúde do Distrito de Manaus, cuja área de abrangência - inicialmente restrita a uma população aldeada distribuída em nove municípios próximos a Manaus - teve sua área de cobertura progressivamente expandida para responder às necessidades de grupos residentes em outras regiões não cobertas pelo convênio. Em cinco anos de atividades do DSEI, a população adscrita pulou de 7 mil para 12.481 pessoas e de nove para 15 municípios. Por ser uma entidade de defesa dos direitos indígenas, a COIAB não teve meios de eximir-se de tais demandas, sendo obrigada a incorporar progressivamente novos usuários, mesmo sem o acréscimo proporcional do custeio para a expansão de suas atividades. Atualmente, a entidade ainda enfrenta o problema da população indígena urbanizada que exerce pressão de demanda sobre o DSEI/ Manaus, mas não dispõe de orçamento para prover seu atendimento.

A distritalização, que vem sendo viabilizada através da $\mathrm{COIAB}$, padece dos problemas anteriormente apontados, sofrendo as conseqüências das crises geradas pelo longo intervalo entre o envio, a análise e aprovação das prestações de contas e a chegada de novos recursos, gerando interrupção do atendimento nas aldeias. Enfrenta também a alta rotatividade de pessoal, pois a grande oferta de postos de trabalho em saúde, em Manaus e municípios próximos, deixa o DSEI em condições de inferioridade para captar profissionais no mercado de trabalho.

Tal cenário compromete a capacidade resolutiva da entidade e o cumprimento de metas e ações programadas, produzindo tensões e insatisfações no plano aldeão que se refletem na sua credibilidade política como um todo. Esses descontentamentos vêm sendo canalizados para as reuniões dos conselhos de saúde, nas quais a satisfação anterior com o processo de distritalização é paulatinamente substituída pela cobrança de resolutividade das necessidades sen- 
tidas pela população indígena. No ano de 2002, a insatisfação sanitária, conjugada a conflitos de parentesco preexistentes ao convênio e que assumiram novas configurações nas disputas pelos recursos de saúde, gerou acusações de improbidade administrativa, formuladas pelos conselheiros indígenas do DSEI/Manaus (Ata da X Reunião do Conselho Distrital do DSEI/ Manaus; 2002), culminando com mudanças na direção da entidade. Ressalte-se que tais dificuldades não são exclusivas da COIAB, elas apenas estão sendo enfocadas para exemplificar um tipo de situação que parece, em maior ou menor grau, comum às convenentes indígenas no Amazonas.

No alto Rio Negro, a situação foi um pouco diferente. Ao longo dos últimos quatro anos, a FOIRN, que inicialmente recusou-se a firmar convênio como prestadora de serviços de saúde, foi paulatinamente pressionada a assumir também as responsabilidades na prestação de cuidados, de tal forma que, a partir de 2003, a instituição recebeu os encargos e recursos para efetuar o atendimento de mais de $90,0 \%$ da população indígena aldeada do Rio Negro.

A análise de Garnelo ${ }^{9}$ demonstra que, após assinatura do convênio para a execução de serviços de saúde, a FOIRN passou a ser uma grande empregadora no Município de São Gabriel da Cachoeira. Sua movimentação orçamentária também cresceu proporcionalmente às novas tarefas. Em 2001, o orçamento dirigido às ações de saúde superou em cinco vezes o gasto com as atividades políticas da entidade. Em 2002, o recurso do convênio foi de $\mathrm{R} \$ 5.700 .000,00 \mathrm{e}$, em 2003, atingiu R $\$ 8.920 .850,00$, ao passo que o orçamento geral da FOIRN para as ações etnopolíticas se manteve em R \$ 1.165.936,00.

A desproporção desses investimentos mostra que o papel de prestadora de serviços de saúde tende a desequilibrar as outras prioridades da entidade numa difícil conciliação entre o perfil de "organização militante" e "organização profissional” 8. Para Magalhães 8, organizações militantes são as organizações exercendo o papel dos movimentos sociais, de contestação. E organizações profissionais são as organizações que passam a estar a serviço dos movimentos sociais.

Cabe-se perguntar sobre as razões que têm levado os dirigentes indígenas a adotar uma opção de alto risco político para o movimento indígena e aceitar uma interface tão profunda e complementar com instituições de um poder de Estado, contra o qual sua história tem se configurado de modo contrastivo.

Em texto anterior, Garnelo \& Sampaio 11 exploraram a motivação das lideranças em acei- tar a pactuação, assimétrica e aparentemente desvantajosa, entre o poder público e o movimento indígena. No supracitado texto, os autores demonstram que tal adesão se deve, principalmente, à busca do protagonismo político negado pela política indigenista e ao desejo de responder às necessidades formuladas por suas bases políticas, boa parte das quais são demandas de interiorização de políticas de governo nas áreas indígenas.

Ao avaliar as razões e conseqüências dessa aliança com o poder público, uma das lideranças envolvidas no processo assim se posicionou:

“É a questão da grande dificuldade que a gente está tendo da compreensão deste modelo de assistência da saúde indígena, dentro da saúde pública. Quer dizer, como é que a UNI-Tefé, o movimento indígena, vai trabalhar com recurso público? Como vai fazer saúde pública lá na comunidade que fica na cabeceira do rio ou afluente de um igarapé? Como é que se vai levar, ou como é a forma que nós temos que usar para repassar esta luta [pela qual] tantas pessoas até já deram a vida, por este movimento indígena? Eu acho que é um momento muito importante que o movimento indígena está tendo; esse programa da saúde indígena é uma oportunidade. É uma escola que você está estudando; que você vai ter um relacionamento com pessoas do município, com a política dos municípios, com a política do Estado, com a política do Brasil.

Eu acho que todos os trabalhos são difíceis, $e$ é muito difícil principalmente na parte técnica, do gerenciamento do recurso, na burocracia da prestação de contas que deve ser prestada com este recurso público [com o qual] a gente está trabalhando. Mas não é por isso que a gente vai dizer não; [vai dizer que] a gente é incapaz de fazer isso. Não vamos [dizer isso] porque todos nós somos capazes.

Agora os problemas vão existir; os problemas existem porque há soluções para eles. E é esse pensamento que cada um de nós, como representantes das organizações indigenas, tem que ter na nossa cabeça. Eu gostaria de frisar aqui uma frase: eu acho que a gente, como índio, se não for capaz de virar a página, não é digno de um livro" (Genival dos Santos Maioruna, dirigente da União das Nações Indígenas de Tefé, gerente indígena do DSEI/Médio Solimões; trechos de discurso proferido no encontro de avaliação dos DSEI, promovido pela COIAB em 2001).

Depoimentos e discursos públicos de lideranças do movimento indígena demonstram a necessidade de manter interações com o mundo não indígena e de criar novos campos de 
aprendizado, de competência técnica, de consenso e de objetivos comuns capazes de dar sustentação a um projeto utópico-político, anteriormente aglutinado na luta pela demarcação de terras e hoje configurado pela busca de novas bandeiras.

"Podemos ter duas maneiras de interpretar o desenvolvimento econômico no mundo de hoje: o primeiro é aquilo que diz respeito puramente à subsistência e aí nós entendemos muito bem, se falarmos na subsistência tradicional. Nossos povos viveram milhares e milhares de anos com isso praticamente completo, de forma harmônica com todos, com a sociedade, com o meio ambiente e os recursos naturais existentes em nosso território. A outra forma de entender é numa lógica mais moderna; digamos, mais na sociedade não indígena que hoje envolve o componente indígena, que é a questão do desenvolvimento econômico... Estamos há quinhentos anos em contato com uma sociedade diferente, que tem uma estrutura pesada e na qual, queiramos ou não, estamos incluídos; estamos dentro desse processo, dentro dessa nova realidade política, social e cultural. Portanto, a subsistência tradicional, em muitos casos, chegou ao seu limite... Surgiram novas demandas, essas novas demandas não são possíveis de ser respondidas apenas com nossas práticas tradicionais; ... daí a necessidade de buscar respostas para esses desafios de hoje, porque nós índios precisamos pensar uma nova concepção, precisamos ter pensamento novo. Nós índios não podemos querer resolver nossos problemas apenas com nossos conhecimentos, com nossas práticas tradicionais" (Gersem Luciano Baniwa, gerente indígena dos Projetos Demonstrativos dos Povos Indígenas; trechos de palestra proferida na III Conferência Nacional de Saúde Indígena, 2001).

As lideranças demonstram também a insuficiência do perfil carismático predominante em fases anteriores do movimento indígena e reafirmam a necessidade de formação de quadros indígenas habilitados para a gestão e o desenvolvimento de novos papéis técnico-administrativos, capazes de viabilizar o desejado protagonismo na gerência de políticas públicas.

“...Que mecanismos nós temos para tentar viabilizar a busca dessas novas soluções? Primeiro, nós precisamos assumir essa responsabilidade; é preciso aprender a trabalhar a responsabilização dos índios. Nós passamos anos, séculos, esperando por respostas, por soluções trazidas pela FUNAI, trazidas pelo Governo, trazidas pelos não-índios. É hora da gente assumir a responsabilidade do nosso futuro. Nós precisamos ser sujeitos compromissados com as soluções dos nossos problemas e não ficar só espe- rando. É interessante a luta, interessante a cobrança, a crítica, mas é importante que também sejamos competentes e capazes de oferecer e de encontrar soluções para os nossos problemas" (Gersem Luciano Baniwa, gerente indígena dos Projetos Demonstrativos dos Povos Indígenas; trechos de palestra proferida na III Conferência Nacional de Saúde Indígena, 2001).

A necessidade de desconstruir o estigma da tutela e da incapacidade política e intelectual que lhes foi atribuído pelo mundo do branco no processo de colonização parece ter levado os dirigentes a valorizar a iniciativa do Ministério da Saúde de estabelecer uma parceria técnico-política, ainda que assimétrica, com suas entidades. Buscaram, assim, inverter o renitente preconceito dos não-índios que, nas suas falas, surgem como sujeitos empenhados em negar a possibilidade de ingerência indígena sobre as políticas públicas.

"Hoje a sociedade nacional, dos brancos, está preocupada por que os índios estão tomando conta do dinheiro [da saúde]. Sociólogos, antropólogos, profissionais de saúde, todos estão preocupados querendo saber o que vai acontecer. Alguns estão torcendo para que avance, outros estão torcendo para que os índios se desgracem lá na frente, e outros querem que índios continuem do mesmo jeito, fiquem sem saber de na$d a$ " (Darcy Marubo, ex-dirigente do Conselho Indígena do Vale do Javari, trechos de discurso pronunciado no Encontro Macrorregional preparatório para a II Conferência de Saúde Indígena, promovido pela COIAB em 2001).

\section{Conclusão}

Os discursos indígenas demonstram uma clara decisão de obter, através do campo da saúde, uma intensificação e aprimoramento da ação política do movimento indígena, numa ação contraditória em que a utopia da autodeterminação é alimentada pela vinculação com o poder de Estado.

As falas indígenas nos levam a perceber o processo de distritalização como campo de poder político, no sentido formulado por Bourdieu 12, ou seja, como um instrumento de comunicação e de transformação da vida social, regulando relações de força entre grupos que ocupam posições diferenciadas no cenário das relações interétnicas, no qual organizações indígenas e entidades governamentais participam de lutas pelo exercício do poder e buscam o reconhecimento de suas proposições como sendo as mais legítimas e legitimadoras do espaço que ocupam. 
Apesar de arriscada e problemática, a terceirização apresenta, aos olhos das lideranças, potencialidades para a ocupação de novos espaços de poder e para buscar a resolução de problemas e propostas de transformação da sociedade através da própria iniciativa indígena, face ao descrédito da capacidade, ou vontade, do Estado em fazê-lo. Tal decisão implica igualmente em mudança nas formas de intervenção social desses agentes sociais, que expressam propósitos de assumir o protagonismo na condução de políticas públicas. Parte desse esforço se traduz na apropriação de conceitos e propósitos do SUS e da racionalidade tecnoburocrática exigida para o manejo de programas e projetos do setor público.

O cenário gerado pela terceirização da saúde indígena é ambíguo e contraditório. Por um lado, a participação propiciada pelo subsistema de saúde indígena enquadra as entidades etnopolíticas em propostas e finalidades preestabelecidas, que não necessariamente favorecem a autonomia e a autogestão e que induzem os dirigentes indígenas a investir no aprendizado da linguagem e de estratégias da tecnoburocracia, em detrimento da lógica e de formas próprias de atuação dos movimentos sociais. Aos dirigentes indígenas é facultado apenas planejar, gerir e executar as ações de saúde que se restrinjam aos limites de sua realidade local/distrital e implementar políticas de governo cuja concepção não foram chamados a participar. Cabe-lhes, ainda, atender as disposições legais que regulamentam a implantação de serviços, com baixa sensibilidade às especificidades culturais das etnias a eles adscritas.

Por outro lado, é inegável que a distritalização propiciou uma interação mais respeitosa entre o Estado brasileiro e as minorias étnicas, o fortalecimento institucional e administrativo das entidades indígenas para o manejo de políticas públicas e a apropriação, por seus líderes, de conceitos e propósitos da reforma sanitária que são indispensáveis à busca da desejada eqüidade no acesso aos serviços de saúde. Apesar dos problemas apontados, observa-se a cria- ção de novos campos de aprendizado e de competência técnica pelas lideranças etnopolíticas, que buscam soluções criativas de problemas gerados na implementação de políticas públicas em áreas indígenas. Esses passam a se constituir como novas bandeiras de luta e de consenso para legitimação política do movimento indígena, tendo como objetivo maior a superação do estigma da tutela e da exclusão histórica de que foram vítimas na construção da sociedade nacional brasileira.

A via de desconstrução do estigma incapacitante, escolhida pelos indígenas, pode ser situada como um exercício de poder simbólico, caracterizado por Bourdieu 12,13 como o poder de (re)construir a realidade através da atribuição de novos sentidos ao mundo social. Assim, a participação no processo de distritalização gera a produção de símbolos e saberes que operam como instrumentos de poder, de comunicação e de transmissão de conhecimentos, nos quais grupos étnicos representados pelas organizações indígenas vêm exercitando a capacidade de "fazer crer", isto é, de fazer valer, para os outros, uma política que não é sua - ou seja, a proposta de implantação dos distritos sanitários - cuja fundamentação e legitimação é exterior à dinâmica do movimento indígena 12 . Os protagonistas dessa iniciativa, por sua vez, se apropriam da lógica do poder de Estado, tentando readequá-la às suas próprias prioridades de grupo civil organizado, ainda que à custa do comprometimento de sua credibilidade política, a fim de "fazer ver" propostas de governo que são parcialmente disponibilizadas para apreciação do cidadão.

Tais iniciativas parecem ameaçadas pela recente movimentação das autoridades sanitárias, que, a partir do ano de 2003, têm mostrado disposição para efetuar uma (re)estatização da atenção à saúde indígena, acenando com a retomada da gestão e execução das atividades sanitárias pelos próprios órgãos de governo e o banimento das entidades conveniadas para um plano secundário do subsistema de saúde indígena. 


\section{Resumo}

O trabalho se propõe a analisar repercussões etnopolíticas, éticas e sanitárias nas práticas das organizações indígenas, conveniadas com o Ministério da Saúde, ligadas ao processo de implantação dos Distritos Sanitários Especiais Indígenas (DSEI) no Estado do Amazonas, Brasil. Os DSEI escolhidos para análise foram o de Manaus e do Rio Negro. As informações trabalhadas são retiradas de relatórios de encontros, reuniões de planejamento e de gestão das convenentes indígenas, da observação participante em eventos de avaliação do processo de distritalização e entrevistas com gerentes indígenas e não indígenas dos DSEI. É discutida a ambigüidade das organizações indígenas de ter que exercer o seu papel político e ao mesmo tempo de executoras de uma política do Estado, assumindo como uma forma de superação do estigma de incapacidade de estar à frente do processo de implantação dos DSEI.

Política de Saúde; Índios Sul-Americanos; Organizações

\section{Colaboradores}

L. Garnelo participou na formulação do projeto de pesquisa, coleta e análise de dados e produção do artigo. S. Sampaio participou na coleta de dados e na revisão final do artigo.

\section{Referências}

1. Langdon EJ. Salud y pueblos indígenas: los desafios en el cambio de siglo. In: Briceño-León R, Minayo MC, Coimbra Jr. CEA, organizadores. Salud y equidad: una mirada desde las ciencias sociales. Rio de Janeiro: Editora Fiocruz; 2000. p. 107-19.

2. Mendes EV. Distrito sanitário. O processo social de mudança das práticas sanitárias do Sistema Único de Saúde. São Paulo: Editora Hucitec/Rio de Janeiro: ABRASCO; 1994.

3. Teixeira CF, Paim JS, Araújo EA, Formigli VL, Costa HG. O contexto político-administrativo da implantação de Distritos Sanitários no Estado da Bahia, Brasil. Cad Saúde Pública 1993; 9:79-84.

4. Teixeira C, Melo C. Construindo distritos sanitários. A experiência da cooperação italiana no município de São Paulo. São Paulo: Editora Hucitec/ Cooperação Italiana; 1995.

5. Noronha JC, Soares L. A política de saúde no Brasil nos anos 90. Ciênc Saúde Coletiva 2002; 6:44550.

6. Laurell AC. Estado e políticas sociais no neoliberalismo. São Paulo: Cortez Editora; 1995.

7. Fernandes R. Privado porém público: o terceiro setor na América Latina. Rio de Janeiro: RelumeDumará; 1994.

8. Magalhães E. O estado e a saúde indígena. A experiência do Distrito Sanitário Yanomami [Dissertação de Mestrado]. Brasília: Universidade de Brasília; 2000.

9. Garnelo L. Poder, hierarquia e reciprocidade: saúde e harmonia entre os Baniwa do Alto Rio Negro. Rio de Janeiro: Editora Fiocruz; 2003. (Coleção Saúde dos Povos Indígenas).

10. Oliveira Filho JP. Ensaios em antropologia histórica. Rio de Janeiro: Editora UFRJ; 1999.

11. Garnelo L, Sampaio S. As bases sócio-culturais do controle social em saúde indígena. Problemas e questões da Região Norte do Brasil. Cad Saúde Pública 2003; 19:311-7.

12. Bourdieu P. O poder simbólico. Rio de Janeiro: Editora Bertrand Russel; 1989.

13. Bourdieu P. A economia das trocas lingüísticas. São Paulo: Edusp; 1996.

Recebido em 10/Fev/2004

Versão final reapresentada em 19/Set/2004

Aprovado em 20/Set/2004 